\title{
My Intership with the City of Los Angeles
}

\author{
MIRIAM THOMPSON
}

Miriam Thompson is in the second year of her MCRP, City and

Regional Planning Department, Cal Poly.

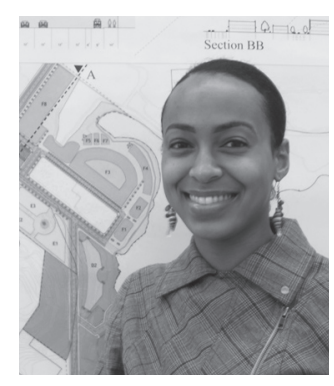

One of CRP's requirements for both the BCRP and the MCRP programs is that students take at least one quarter of professional intership, which is usually done during summer. Miriam Thompson writes about her internship with the Plannig Department of the City of Los Angeles, where she learned more about sustainability, her main interest.

There is a consensus in academia about the importance of internships. An internship can be an extremely valuable opportunity to apply and expand your existing knowledge base as well as increase your professional contact base. The first year of the California Polytechnic State University (Cal Poly), San Luis Obispo Master's of City and Regional Planning (MCRP) Program equips its students with a first-rate set of fundamental planning knowledge and skills However, no matter how well the course work prepares its budding professionals, it is the real world application of this knowledge that truly allows us to realize the full value and breadth of our education.

As a $2^{\text {nd }}$ generation Angelino, I have a lifelong vested interest in the City of Los Angeles. I consider myself very fortunate to have landed an internship in my future home, which also happens to be, the second largest city in the United States. As such, innovative planning projects abound. Consequently, there is substantial competition for internship placements, so imagine my zeal when I learned that I was hired to work for the City of Los Angeles Department of City Planning (LADCP).

Being offered this position was a result of networking, the MCRP program's reputation, and my polished verbal and visual presentation. In the months preceding my acceptance to Cal Poly, I attended a number of networking events and exchanged business cards with people in the planning field. Then, after preparing and designing a resume, cover letter, writing sample, project experience list and reference list I emailed everyone whose business card I received. Of the few responses, one from the Executive Director of the US Green Building Council-Los Angeles Chapter proved promising. He informed me that his colleague Claire Bowin (AICP, LEED AP) was looking for an intern at LADCP and gave me her contact information. After analyzing my resume and an informal interview, she hired me.

My new supervisor, Claire Bowin, informed me that I would be working with her on a LEEDND Pilot specific plan. My undergraduate study of sustainable design formed the basis for my initial interest in the optimization of the built environment, which I carried to my graduate studies at CRP. As I began to contemplate the negative impacts of traditional development patterns, my interest in finding better-quality alternatives peaked; my internship would allow me to deal exactly with this issue.

\section{Major Assignments}

During my tenure with LADCP, my most significant contribution was a multifaceted parking study for the Cornfield Arroyo Seco Specific Plan (CASP). The plan is one of only two public projects participating in the new U.S. Green Building Council (USGBC) Leadership in Energy 
and Environmental Design Neighborhood Development (LEED-ND) Pilot Program. As I begun to realize the comprehensive nature of the benefits that the CASP will provide I became inspired to learn more about the process and contribute to its development.

One of my responsibilities was to collect data on the number of parking spaces within the 603-acre area. I was also to analyze additional parking data and researching strategies for reducing the parking footprint. First, I conducted an extensive visual survey of the area using the Zoning Information Map Access System (ZIMAS), Navigate LA and Google Maps. I then prepared Graphic Information System (ARCGIS) maps and Microsoft Excel charts to convey the results to the Graphics division. This data allowed me to calculate and project the area's current and potential parking supply vs. demand. Once I established this baseline data, it was incorporated into my supervisor's larger model. I then conducted a sensitivity analysis on this model, inputting variations in the parking variables. From this analysis, we were able to discern the effect minimum or maximum parking policies would have on the CASP area.

Overall my work proved to be a valuable contribution to the planning process. To be held accountable for decisions on this level of responsibility and liability was new territory for me. Yet I am confident that the education I received during the first year of the Cal Poly MCRP program prepared me to take these challenges head on.

In addition to my research requirements, I attended a series of important collaborative meetings with representatives from over ten affiliates. For example, there were representatives from the consultant team, Council District, State Parks and Recreation, GIS department, Urban Design Studio, Private Developers, etc. The meetings were interesting because they allowed me to gain firsthand experience on how the staff interacted with one another and what level of responsibility planners have for their respective specialties. In addition to these in house meetings, I participated in a community meeting for public comments on the draft of the specific plan. I helped answer questions of community members and helped with the display boards of highlighted information on the specific plan.

\section{Lessons Learned}

In retrospect, this internship surpassed my expectations and I hold the experience in high regard. At the end of the summer, I had a number of new interpersonal and technical skills, which make me more confident in my preparedness to adapt to a variety of planning responsibilities. I also gained a wealth of knowledge during this internship; not only from my assignments but also from observing the office culture, management style, and type of people that are in the trenches of LADCP. In terms of my professional development, it was very motivational to witness my role models in action and have a concrete understanding of the career paths available to me. 